\title{
03 - A GARNIERITA DA MINA ONÇA-PUMA, CARAJÁS, PARÁ
}

http://gmga.com.br/03-a-garnierita-da-mina-onca-puma-carajas-para/

\subsection{9/ISSN.2594-942X.v52018i1a3OJCF}

\section{CHOQUE FERNANDEZ, Oscar Jesus ${ }^{1}$}

${ }^{1}$ Instituto Federal do Pará, IFPA-Campus Belém, Prof. Dr. Curso Técnico em Metalurgia/Engenharia de Materiais, oscar.fernandez@ifpa.edu.br

\begin{abstract}
Initially a survey was made on the mineralogical use of the term garnierite, the same is used in the field to designate all the greenish Ni-phyllosilicates when a more specific characterization is not possible. Thus, garnierites were studied from the saprolite ore from the lateritic nickel deposit of the Onça-Puma, State of Pará. The lateritic ore fragments showed an intimate association of serpentines with iron oxides, quartz and sometimes clay minerals, occurring as boxwork type meshes and fine filler veins. The phases lizardite and/or chrysotile, maghemite, quartz and nontronite were identified. Due to their chemicalmineral composition these phases are typical Ni-serpentinites.
\end{abstract}

Key-words: serpentin, nickel, lizardite, chrysotile

\section{INTRODUÇÃO}

A garnierita foi dado ao nome de uma especie mineral descoberta em 1863 em Nova Caledônia, sendo mais tarde provado que a mesma é uma mistura de diferentes silicatos hidratados de níquel (Pecora et al. 1949, Faust 1966 apud Villanova-de-Benavent et al. 2016). O termo garnierita é genérico para o minério de niquel esverdeado o qual foi formado como resultado de intermperismo laterítico de rochas ultramáficas (serpentinito, dunito e peridotito). Hoje é amplamente usado na literatura para se referir a um grupo de filosilicatos de magnésio portadores de níquel, pobremente cristalizados, finamente granulados e esverdeados. A garnierita ocorre como misturas de silicatos placosos de $\mathrm{Ni}$ e de magnesio portandores de Ni (Faust 1966, Brindley e Hang 1973, Springer 1974, Brindley 1978, Villanova-de-Benavent et al. 2014a, apud Villanova-de-Benavent et al. 2016, Wells et al. 2009).

Assim, em sendo um nome mineral não valido, a garnierita chegou a ser um termo conveniente usado em campo para designar todos os filosilicatos de Ni esverdeados, quando não é possivel uma caracterização mais especifica (Brindley 1978), e muitos autores usão esse termo com esse significado genérico (Moraes 1935, Pecora e Hobbs 1942, Pecora et al. 1949, Varela 1984, Gleeson et al. 2003, 2004 apud Villanova-de- 
Benavent et al. 2016, Freyssinet et al. 2005, Wells et al. 2009).

Adicionalmente a classificação e nomes dos minerais da garnierita, representa uma longa e complexa controversia, isto debido à natureza de grão fino, pobre cristalinidade e ocorrencia frequente como mistura intima de diferentes especies minerais (Brindley e Hang 1973 apud Villanova-de-Benavent et al. 2016). Brindley e coautores distinguiram as seguintes series $\mathrm{Mg}-\mathrm{Ni}$ : minerais do grupo da serpentina i) lizardita-népouita, ii) crisotila-pecoraita e iii) berthierina-brindleyita; estruturas tipo talco iv) talcowillemseita e v) "kerolita"-"pimelita"; vi) series clorita clinocloro-nimita; e finalmente, vii) sepiolitafalcondoita (Brindley e Hang 1973, Brindley e Maksimovi? 1974, Brindley 1978, 1980 apud Villanovade-Benavent et al. 2016).

A mais comum das garniertitas encontradas na natureza são formadas por lizardita-népouita e "kerolita"-"pimelita" (Brindley 1978), e muitos autores tem se referido os mesmos como garnierita "tipo serpentina" (ou "tipo $7 \AA$ ^) e "tipo talco" ("tipo $10 \AA$ ^”), respectivamente (Brindley e Hang 1973, Brindley e Maksimovi? 1974, Galí et al. 2012 apud Villanova-de-Benavent et al. 2016, Wells et al. 2009).

"Kerolita" e "pimelita" podem ser descritas como fases com afinidade para talco com água extra em sua estrutura, dentro da formula estrutural ideal $[(\mathrm{Mg}, \mathrm{Ni}) 3 \mathrm{Si} 4 \mathrm{O} 10(\mathrm{OH}) 2 \cdot \mathrm{n}(\mathrm{H} 2 \mathrm{O})]$. Faust (1966) classificou a "pimelita" dentro do grupo esmectita, já outros autores especifiquem que nem "kerolita" ou "pimelita" exibam aumento intracristalino (Kato 1961, Brindley e Hang 1973, Brindley 1978 apud Villanova-deBenavent et al. 2016). Ambas as especies foram desacreditadas pela Commission on New Minerals, Nomenclature and Classification of the International Mineralogical Association (CNMNC-IMA), esses nomes tem sido usados durante decadas (Gleeson et al. 2003, Tauler et al. 2009, Galí et al. 2012, Villanova-de-Benavent et al. 2014a, Cathelineau et al. 2015 apud Villanova-de-Benavent et al. 2016, Freyssinet et al. 2005 e Wells et al. 2009) e são consideradas especies validas pela International Association for the Study of Clays (AIPEA). De acordo com Dosbaba e Novák (2012, apud Villanova-deBenavent et al. 2016), "kerolita" representa uma variedade de talco hidratado, pobremente ordenado e finamente cristalino, sendo distinguido da esmectita por apresentar picos largos em aproximadamente 10 Å, e pela absoluta falta de aumento em atmôsfera de etileno glicol (Brindley e Brown 1980 apud Villanova-de-Benavent et al. 2016).

Descoberta na década de 1970, a exploração do níquel lateritico nos depósitos de Onça-Puma/PA iniciou a produção de ligas de ferroníquel desde meados de 2011. O Projeto Onça-Puma foi adquirido pela Vale em novembro de 2005, visando aproveitar depósitos de níquel laterítico, um tipo de minério encontrado mais próximo à superfície em regiões quentes e úmidas (VALE 2009). Muitos autores (Silva 1995, Macambira 2001, Wells et al. 2009) sugerem que as feições esverdeadas encontradas nos lateritos desses depósitos contenham fases com níquel.

Este trabalho analisou amostras de minério de niquel da mina de Onça-Puma fornecendo um exame do silicato de Mg-Si hidratado ocorrendo em minério laterítico exposto na frente de lavra, fornecendo novas informações sobre a mineralogia das fases distinguidas pela cor verde.

\section{MATERIAIS E MÉTODOS}


As amostras foram coletadas na mina de Onça-Puma, em visita de campo realizada em 2012. As mesmas correspondem às amostras OPAA2 e OPAB1 da frente de lavra e OPA-RET da operação da Homogeneização-Estocagem (Retomadora).

Para caracterizar as garnieritas alem da lupa, foram usadas a microscopia ótica de luz transmitida, para isso foram preparadas lâminas delgadas; análises por difração de raios-X pelo método do pó, sendo os fragmentos das amostras devidamente preparados e usando os difratometros Philips PW 1050, do Instituto Federal de Educação, Ciência e Tecnologia do Pará (IFPA) e X'Pert PRO da PANalytical do Instituto de Geociências da Universidade de Halle.

\section{RESULTADOS E DISCUSSÃO}

A frente de lavra esta constituído por dois tipos de minérios: "A" maiores teores de níquel (em relação B) e "B" teores de níquel mais baixos. O ROM da mina é constituído pelos minérios AA e AB (Figura 1). 


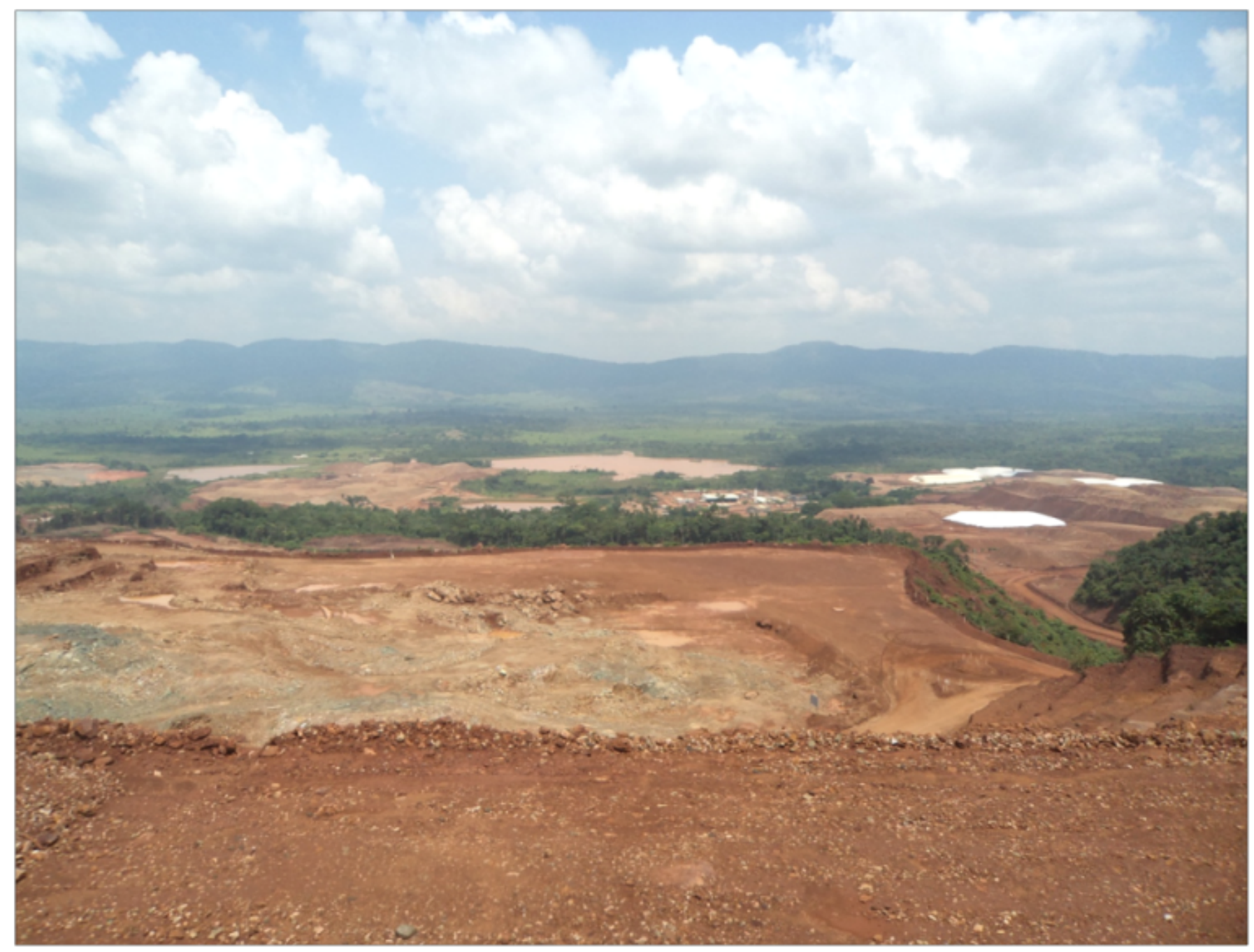

Figura 1. Frente de lavra da mina Onça-Puma.

Os fragmentos saprolíticos das amostras de mão da frente de lavra (OPAA2, OPAB 1) e da retomadora (OPARET) da mina de Onça-Puma (Figura 2) são friáveis a moderadamente endurecidas, porosas, com feições em camadas e veios com tonalidade marrom a esverdeada, com tamanhos milimétricos a centímetros, por vezes ocorrem manchas escuras junto as camadas esverdeadas (Silva 1995, Macambira 2001, Wells et al. 2009). 


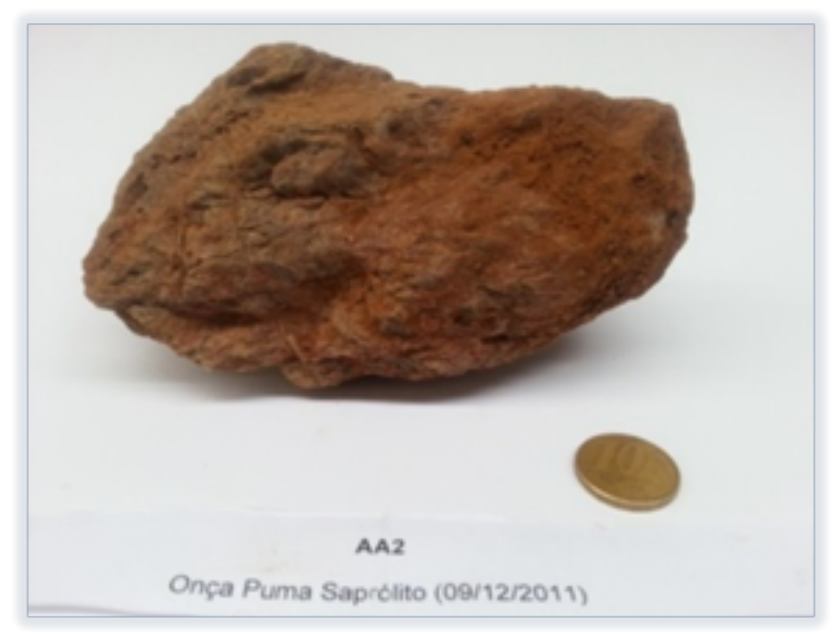

Figura 2A. Amostra de mão do minério laterítico da mina Onça-Puma OPAA2.

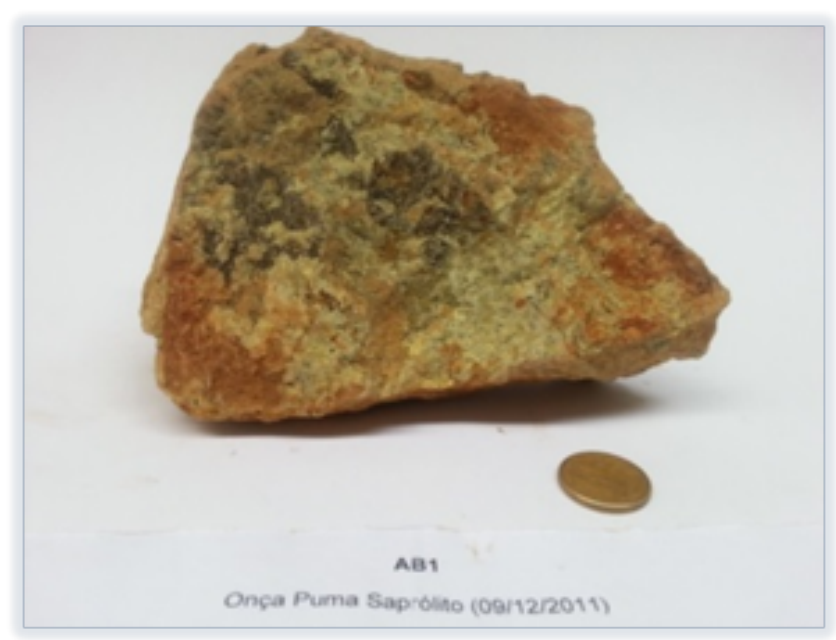

Figura 2B. Amostra de mão do minério laterítico da mina Onça-Puma OPAB1. 


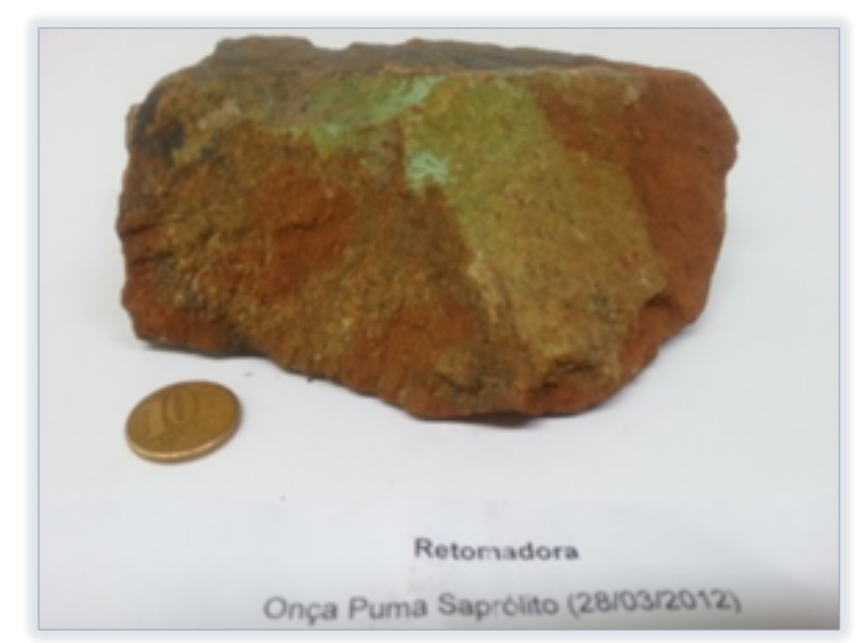

Figura 2C. Amostra de mão do minério laterítico da mina Onça-Puma OPARET.

As amostras provenientes da zona saprolítica apresentam mineralização tipicamente garnierítica. Ao microscópio mostram serem fases de serpentinas com brilho e tonalidades esverdeadas. Apresentam intercrescimento ultrafino formando malhas (tipo texturas box-work Freyssinet et al. (2005)) (Figura 3a), microveios e microfibras. Segundo Wells et al. (2009) estes tipos de feições das serpentinas, são geralmente referidos como garnieritas, o que demonstra a origem das lateritas, isto é, rochas ultramáficas. As malhas apresentam tábuas zonadas demostrando que pode ocorrer variação química. A zonação se manifesta melhor com os nicóis cruzados (Figura 3b). 


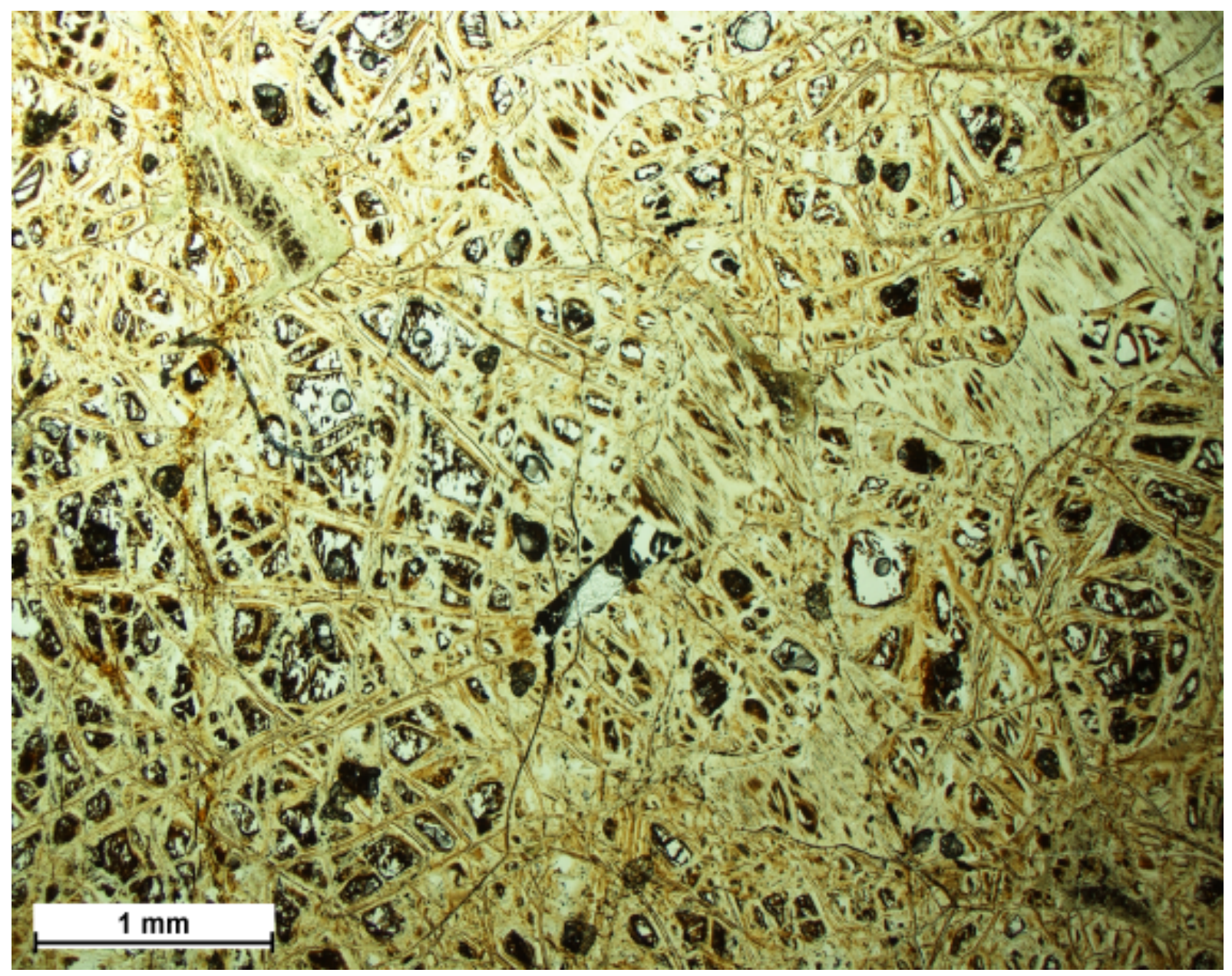

Micrografia com malhas de serpentina, tabuas zonadas e fibras. 


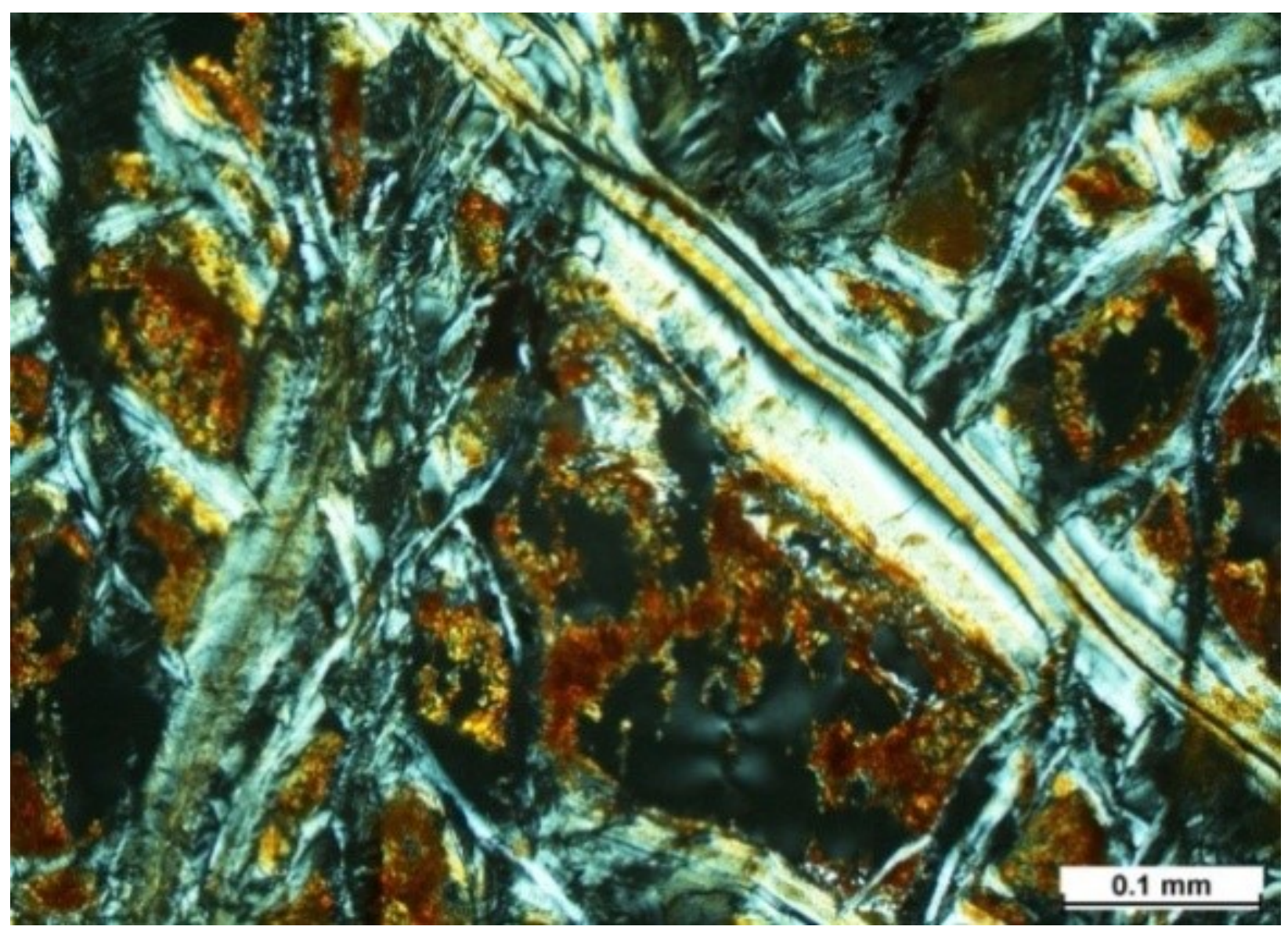

3B. Detalhe da zonação das malhas. Imagens de luz transmitida, b nicóis //, c nicóis X. Aumentos de 25x e 40x respectivamente. 


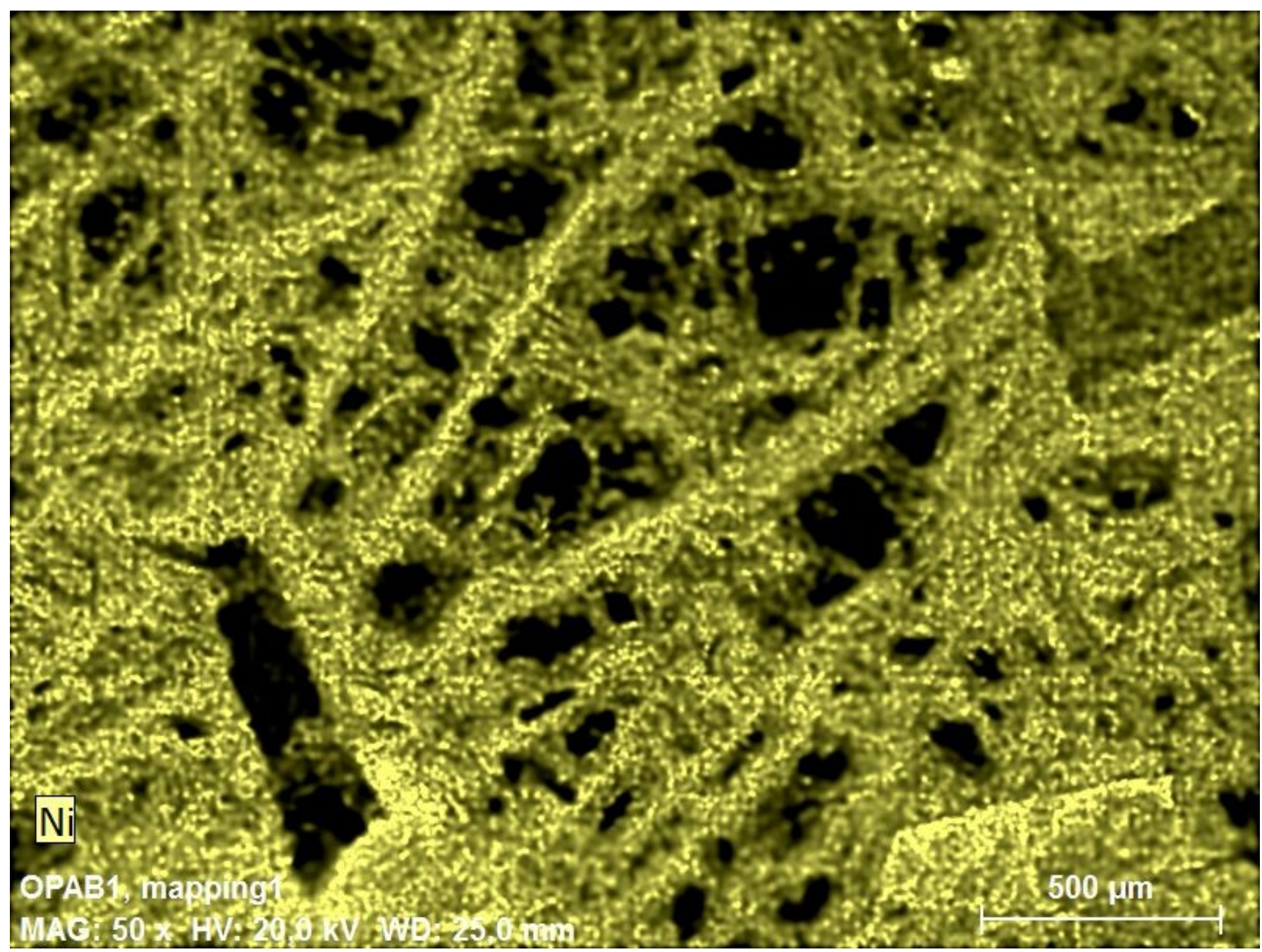

Figura 3C. Mapa de uma seção de amostra laterítica com presença de níquel.

Por difração de raios-X, os espectros difratométricos mostram reflexões bem definidas a amostra OPAA2, mostra (Figura 4) as serpentinas, quando comparadas com os seus padrões difratométricos, sugerem ser principalmente as fases lizardita $\left[(\mathrm{MgFe})_{3}\left(\mathrm{Si}_{2} \mathrm{O}_{5}\right)\right] .(\mathrm{OH})_{4}(\mathrm{PDF}: 00-011-0386)$ e/ou crisotila $\left[\mathrm{Mg}_{3}\left(\mathrm{Si}_{2} \mathrm{O}_{5}\right)\right] .(\mathrm{OH})_{4}(\mathrm{PDF}: 00-002-0094)$, associadas com maghemita (?-- $\left.\mathrm{Fe}_{2} \mathrm{O}_{3}\right)(\mathrm{PDF}: 01-089-5892) \mathrm{e}$ quartzo $\left(\mathrm{SiO}_{2}\right)$ (PDF: 00-005-0490). Foi observado a esmectita (provavelmente nontronita) (PDF: 00-002-0026). Ocorre sobreposição de picos na serpentina, o que torna difícil a identificação precisa das fases, podendo ocorrer também nepouíta $\mathrm{Ni}_{3} \mathrm{Si}_{2} \mathrm{O}_{5}(\mathrm{OH})_{4}$. Para as amostras OPAB1 e OPARET as fases são as mesmas com exceção do quartzo que só se apresenta na OPAA2.

Nas amostras estudadas não foram observados minerais de níquel, entretanto o mapa realizado sobre uma seção mostrou presença de niquel disseminado (figura 3c), indicando que este metal se encontra em fases portadoras de níquel, as quais correspondem aos minerais do grupo da serpentina, principalmente lizardita e/ou crisotila. Essas fases são de difícil diferenciação por DRX, pois apresentam sobreposição de reflexões, principalmente nos seus picos principais 2?: $12^{\circ}$ e $22^{\circ}$. Se bem que as amostras estudadas se mostram como evidentes fases portadoras de níquel, também pode ser observado que há variação 
mineralógica entre elas, ocorrendo maghemita em todas as amostras, porém em apenas uma delas inclui quartzo. Alguns autores como Silva e Oliveira (1995), Macambira (2001), Freyssinet et al. (2005) sugerem a presença de esmectita (nontronita/ montmorilonita), no presente trabalho, e nas amostras estudadas, a mesma pode ser encontrada na OPAA2 (em 2?: $\left.5^{\circ}\right)$, porém as suas reflexões encontram-se mascaradas pelas outras fases maioritárias, mesmo pelo background ou mesmo por fases amorfas.

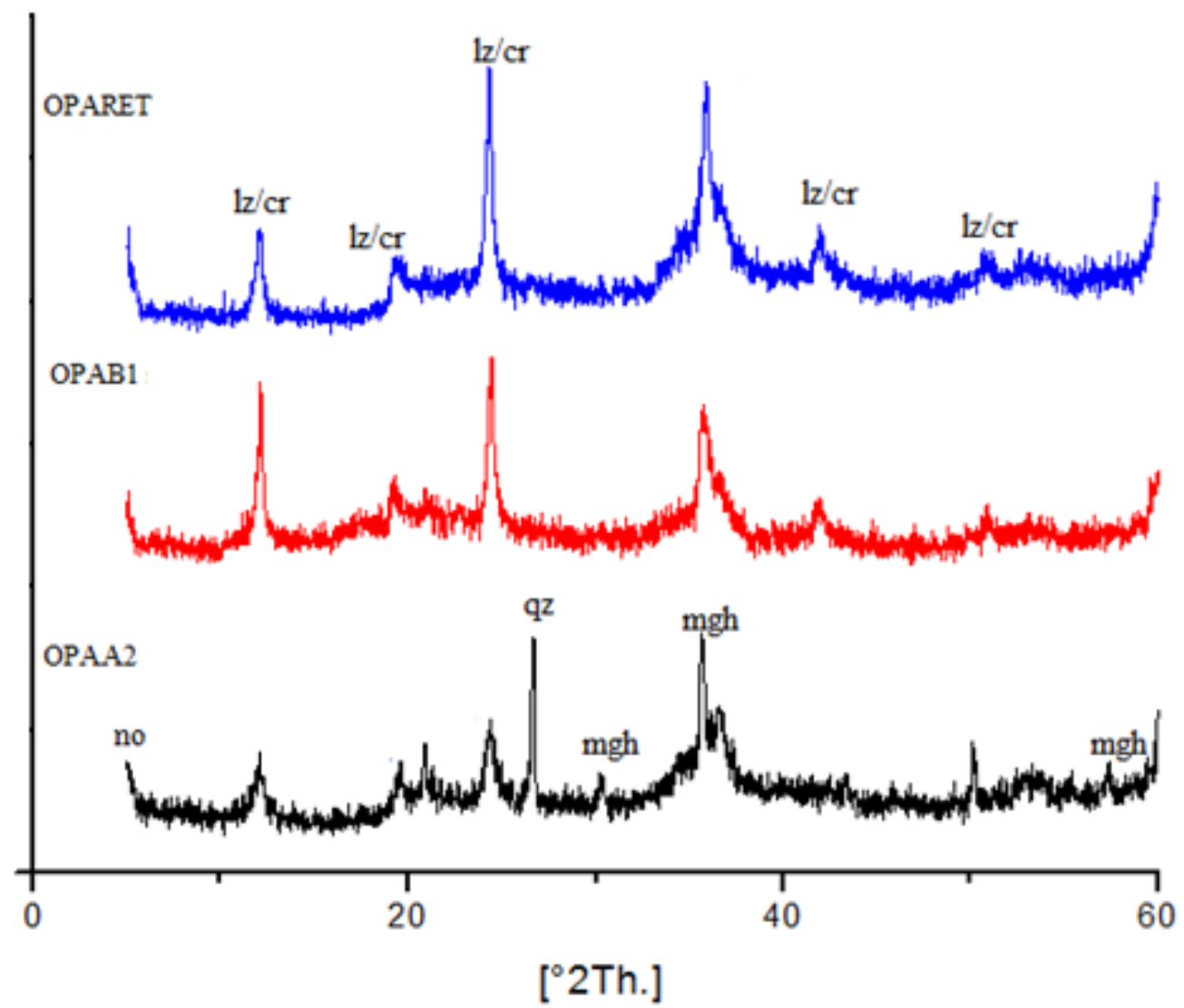

difratométricos das amostras OPAA2, OPAB1, OPARET.

Figura 4. Espectros lz/cr: lizardita/crisotila, mgh: maghemita, qz:quartzo, no:nontronita.

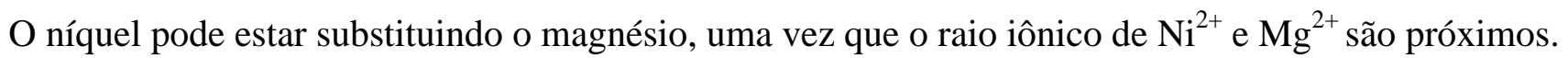
Este fato é mais ocorrente quando ocorre lateritas com elevados teores de $\mathrm{Mg}$, como é o caso das amostras de Onça Puma com teores aproximados de 30\% de MgO. Quando o níquel substitui o magnésio, mostra ligações fortes, tornando metalurgicamente difícil a redução. A velocidade de redução é maior devido estar relacionada à diminuição da atividade termodinâmica do NiO (Li 1999).

\section{CONCLUSÕES}


A garnierita de Onça-Puma estudada no presente trabalho está constituída por lizardita e/ou crisotila. Não foram observados minerais de níquel. Essas fases, pela sua composição química-mineral, são serpentinas portadores de níquel.

Pelos resultados analíticos obtidos pode ser concluído que no minério garnierítico há uma mistura de fases, análogas com serpentinas, esmectitas e óxidos de ferro. As análises feitas sobre essas misturas sugerem que ela tem fases complexas e heterogêneas. Entre as mesmas amostras existe variação mineralógica mostrando serpentina e serpentina-esmectitas.

\section{AGRADECIMENTOS}

À empresa Onça-Puma (VALE) pela doação do minério laterítico utilizado neste trabalho. Ao CNPQ, projeto CNPQ-VALE No. 55037/2012-4, Chamada N 05/2012. Ao CNPQ pela bolsa de pesquisa. Ao Grupo de Mineralogia e Geoquímica Aplicada (GMGA) da Universidade Federal do Pará (UFPA) pela preparação das lâminas polidas. Ao Prof. Dr. Herbert Pöllmann do MLU- Universidade de Halle, Alemanha pelas análises por DRX.

\section{REFERÊNCIAS}

Freyssinet, P.; Butt, C.R.M.; Morris, R.C.; Piantone, P. 2005. Ore-forming processes related to lateritic weathering. In: CSIRO Exploration and Mining, Kensington., editor/s. Economic Geology 100th Anniversary volume; 2005; 681-722.

Li, S. 1999. Study of Nickeliferous Laterite Reduction. Open Access Dissertations and Theses. McMaster University DigitalCommons@McMaster.

Macambira, E. 2001. Projeto platina e associados prospecção geológica e geoquímica no corpo maficoultramáfico da Serra da Onça-Pará. CPRM. Informe de Recursos Minerais, Série Metais do Grupo da Platina e Associados, 26.

Silva, M.L.M.C.; Oliveira, S.M.B. 1995. As fases portadoras de níquel do minério lateritico de níquel do vermelho, serra dos Carajás (PA). Revista Brasileira de Geociências. Vol 25, março de 1995.

VALE, 2009. Site institucional. Disponível em: < http://www. vale.com/vale>. Acessado em 07 de agosto de 2012.

Villanova-De-Benavent, C; Nieto, F.; Viti, C.; Proenza, J.A.; Galí, S. 2016. Ni-phyllosilicates (garnierites) from the Falcondo Ni-laterite deposit (Dominican Republic): Mineralogy, nanotextures, and formation mechanisms by HRTEM and AEM. American Mineralogist 101 (6):1460-1473

Wells, M.A; Ramanaidou, E.R; Verrall, M.; Tessarolo, C. 2009. Mineralogy and crystal chemistry of 
"'garnierites" in the Goro lateritic nickel deposit. New Caledonia. Eur. J. Mineral. 21:467-483, Published online January 2009.

PDF generated by Kalin's PDF Creation Station 